\title{
LADAINHA $^{1}$ EM LOUVOR A SÃO MIGUEL DA COMUNIDADE TAUERÁ DE BEJA (ABAETETUBA/PA)
}

\author{
Jocenilda Pires de Sousa do Rosário ${ }^{2}$ \\ Samuel Antonio Silva do Rosário ${ }^{3}$ \\ Rilvanda Maria Pires Santos ${ }^{4}$
}

Há quase um século uma prática cultural e religiosa ocorre na localidade chamada Tauerá de Beja, zona rural do município de Abaetetuba, Pará, Brasil. Trata-se da ladainha em homenagem a São Miguel, o anjo guerreiro. Uma característica marcante e bem peculiar dessa festa religiosa é a prática de cantar ladainhas de maneira tradicional com vozes bem divididas e utilizando-se de palavras em latim vulgar, algo que se mantém há gerações e que acabou se tornando uma das essências dessa tradição religiosa, misturando devoção e memórias.

A referida prática religiosa confunde-se com a própria história da família Pires, família com a qual a tradição, em particular, originou-se na localidade e que tem se mantido firme durante anos. É um momento de celebrar a fé e o reencontro familiar. Neste sentido,

as festas revelam a essência fundante de respeito à fé e à fraternidade comunal, que alimentam as manifestações religiosas e perpetuam as tradições que constituem um verdadeiro patrimônio cultural (JURKEVICS, 2005, p. 74).

Segundo informações ${ }^{5}$, a tradição teria iniciado por meio de uma missa em homenagem ao santo, realizada no barracão São Miguel, pertencente à família Pires, sempre no terceiro domingo do mês de outubro de cada ano. Celebrada em latim, pelos padres italianos que haviam chegado a Abaetetuba, a tradição, desde essa época, já era prestigiada por muitas pessoas da comunidade Tauerá de Beja. Com o passar dos anos, os padres não celebraram mais a missa como de costume, em virtude da construção de uma igreja, na mesma comunidade, que homenageava outros santos. Nesse novo cenário, é iniciada a tradição da ladainha cantada em louvor a São Miguel, feita pelos próprios membros da família Pires que aprenderam a tradição com seus antepassados.

\footnotetext{
${ }^{1}$ Prece em forma de invocação sucessiva (Minidicionário prático: língua portuguesa de A/Z. São Paulo: DCL 2010. p. 192).

${ }^{2}$ Doutoranda em Estudos Literários pelo Programa de Pós-Graduação em Letras da Universidade Federal do Pará. E-mail: joufpa16@gmail.com

${ }_{3}^{3}$ Mestre pelo Programa de Pós-Graduação em Linguagens e Saberes na Amazônia da Universidade Federal do Pará - Campus Bragança. Professor EBTT do Instituto Federal de Educação, Ciência e Tecnologia do Pará (Campus Marabá Industrial). E-mail: samuel mat2009@hotmail.com

${ }^{4}$ Especialista em Análise Literária pela Universidade da Amazônia. E-mail: rilvanda@gmail.com

5 Informações obtidas por meio de entrevistas realizadas em julho de 2018, com Plínio Baía Pires, Leontina Baía Pires, Elza Pires de Sousa, Élida Pires e Dorival Pinheiro.
} 
No início, José Luís Pires era quem liderava a voz masculina durante o canto, recebendo a denominação de Capitulante $^{6}$ e Benedita Pires liderava a voz feminina ao responder a ladainha e, por esta função, recebia a denominação de Cabeçária ${ }^{7}$. Com o passar do tempo, houve a necessidade de contratar um grupo de rezadores, visto que os filhos, já idosos, não conseguiam mais firmar as vozes durante o canto. Vale ressaltar, que outras vozes foram se firmando com o passar dos anos, como a de Élida Pires (filha de José Luís Pires) que hoje exerce a função de Cabeçária, após ter aprendido a tradição com seu pai.

A ladainha em homenagem a São Miguel é um momento religioso, mas também um momento de comunhão familiar. Nesse sentido, mencionamos a importância de manter viva esta tradição que resgata o passado ao manter vivas as memórias familiares. Assim, “A memória coletiva é um instrumento revelador para as intenções e experiências [...]. Ela abre espaço para a paixão, o afeto, a comunicação do ser/estar junto" (LUÍNDIA, 2001, p. 09). Além disso, ressaltamos a devoção ao santo o que prolonga a ladainha cantada em latim vulgar, transmitida de geração a geração e que ainda está presente nesta comunidade.

\section{REFERÊNCIAS}

JURKEVICS, Vera Irene. Festas religiosas: materialidade da fé. História: Questões \& Debates, Curitiba, n. 43, p. 73-86, 2005. Editora UFPR.

LUÍNDIA, Luiza Elayne Azevedo. Festas, festas de santo: rituais amazônicos. INTERCOM - Sociedade Brasileira de Estudos Interdisciplinares da Comunicação, XXIV Congresso Brasileiro da Comunicação - Campo Grande /MS - setembro, 2001.

\footnotetext{
${ }^{6}$ Termo usado pelos entrevistados para denominar a função exercida no momento da ladainha.

${ }^{7}$ Termo usado pelos entrevistados para denominar a função exercida no momento da ladainha.
} 

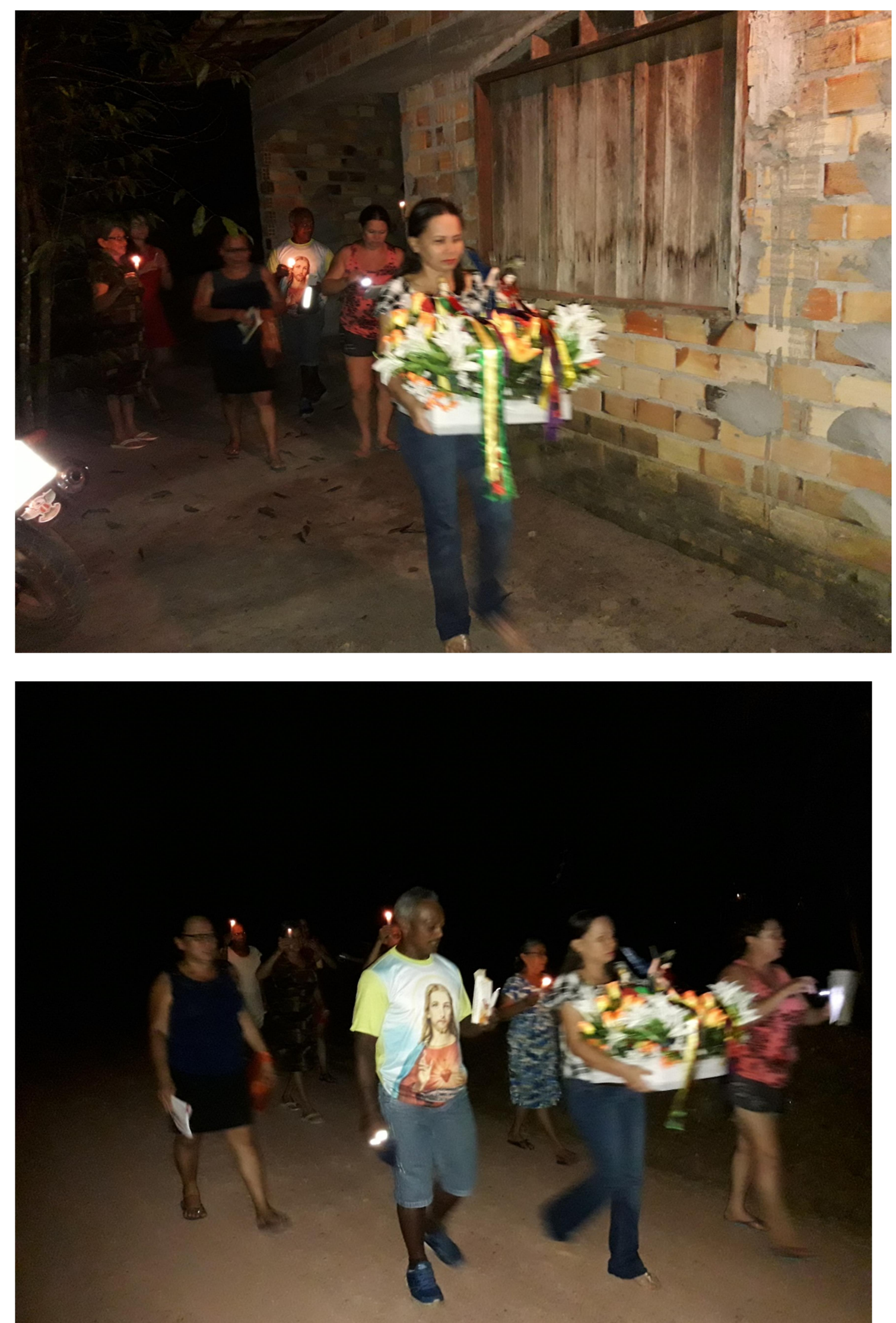

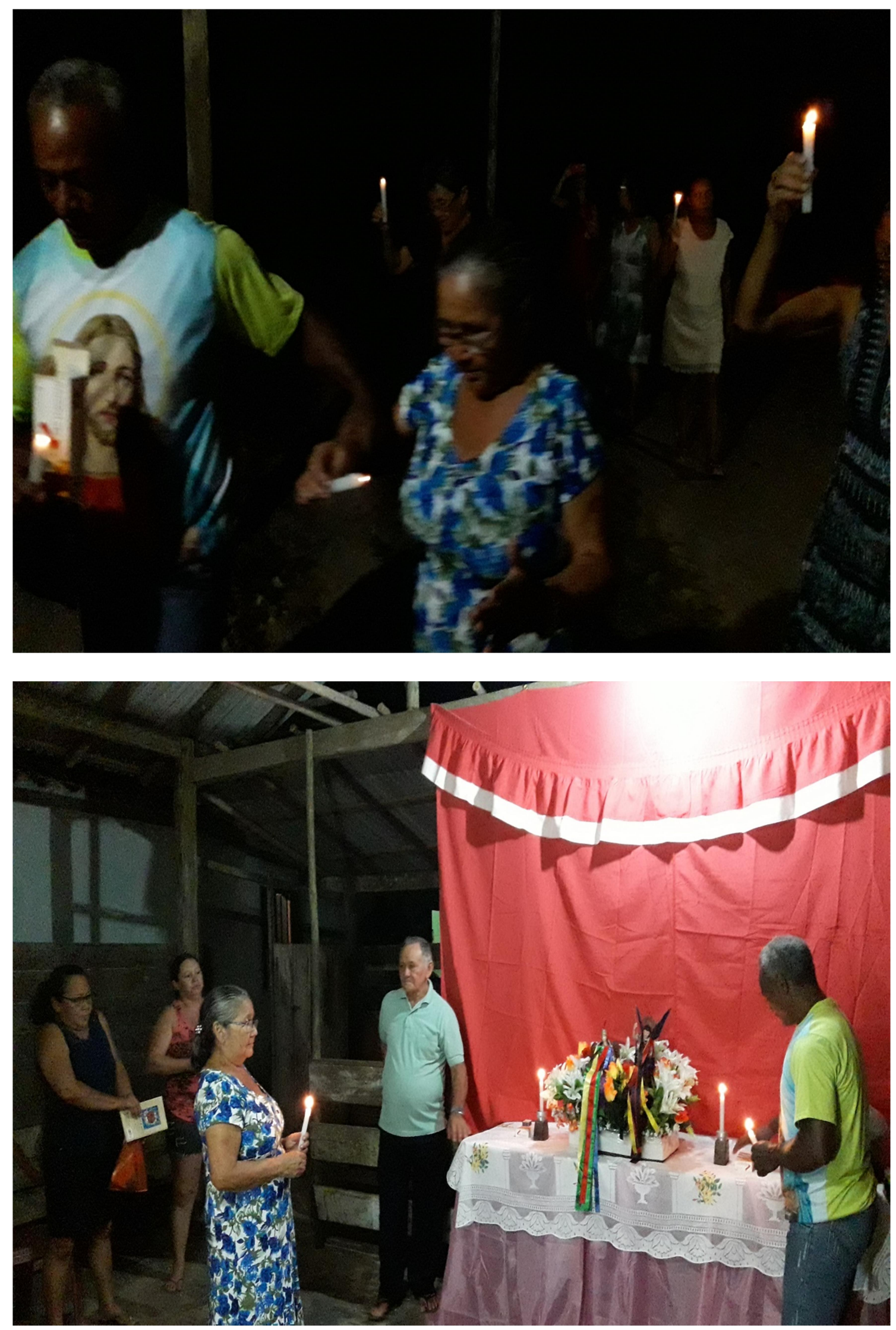

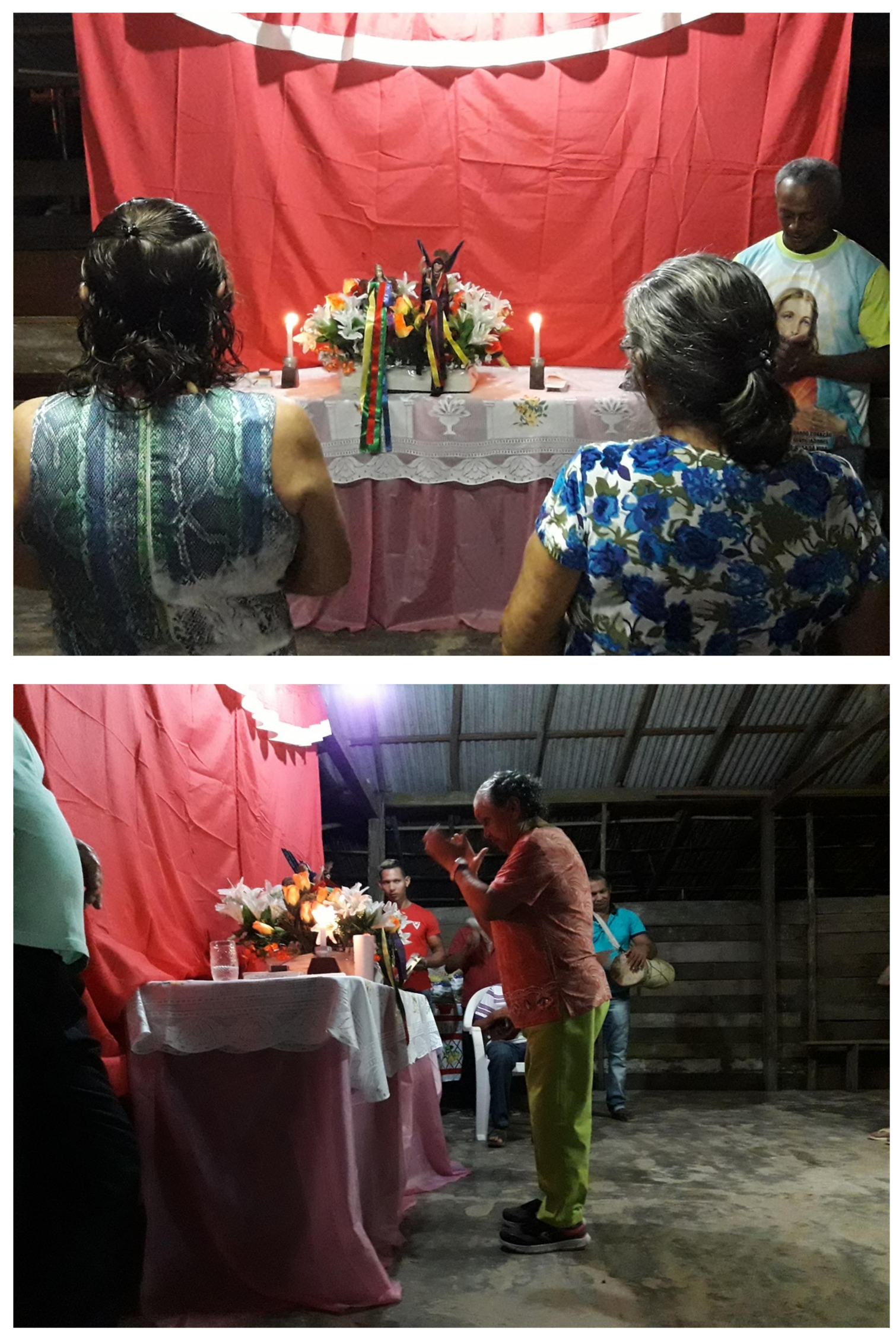

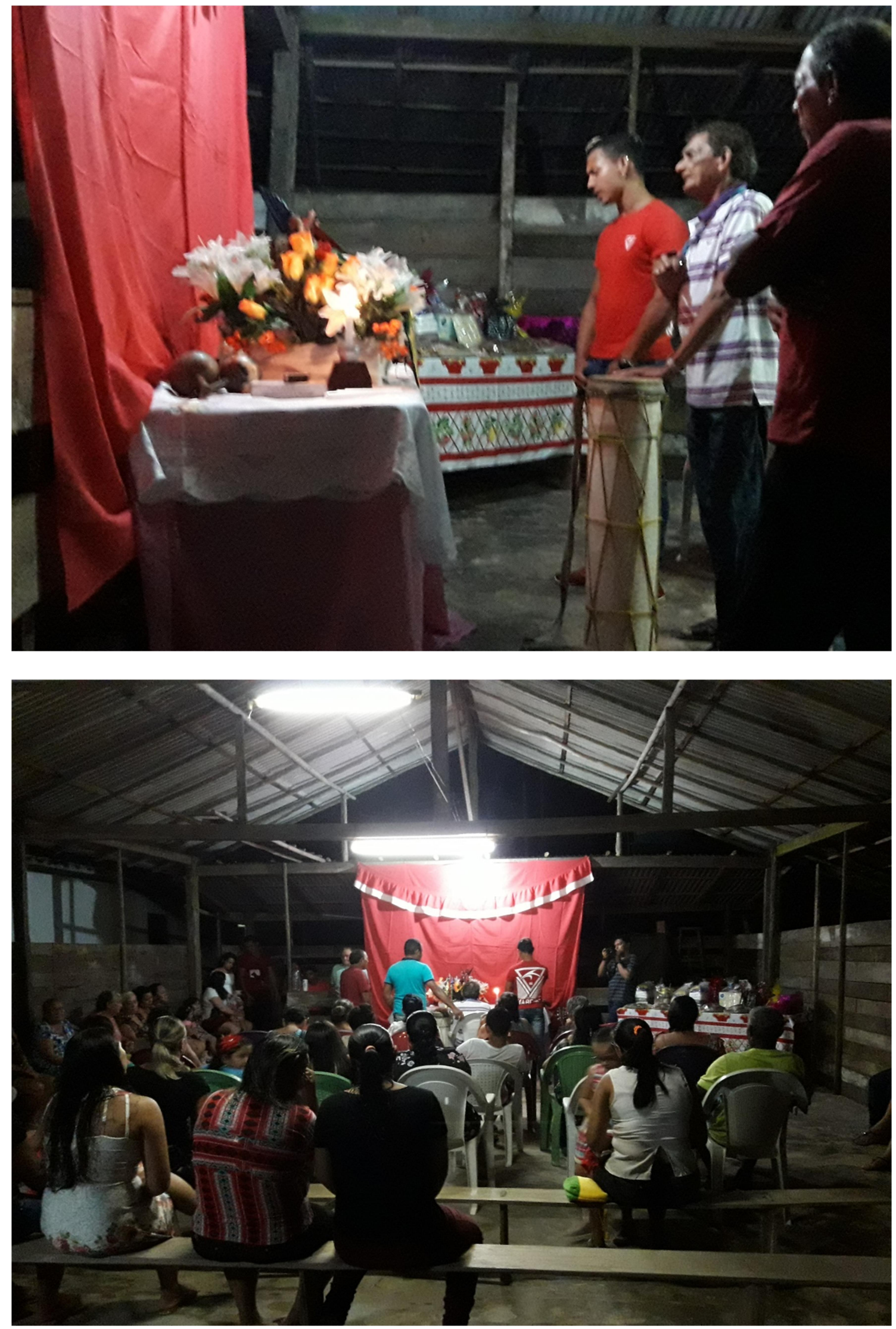

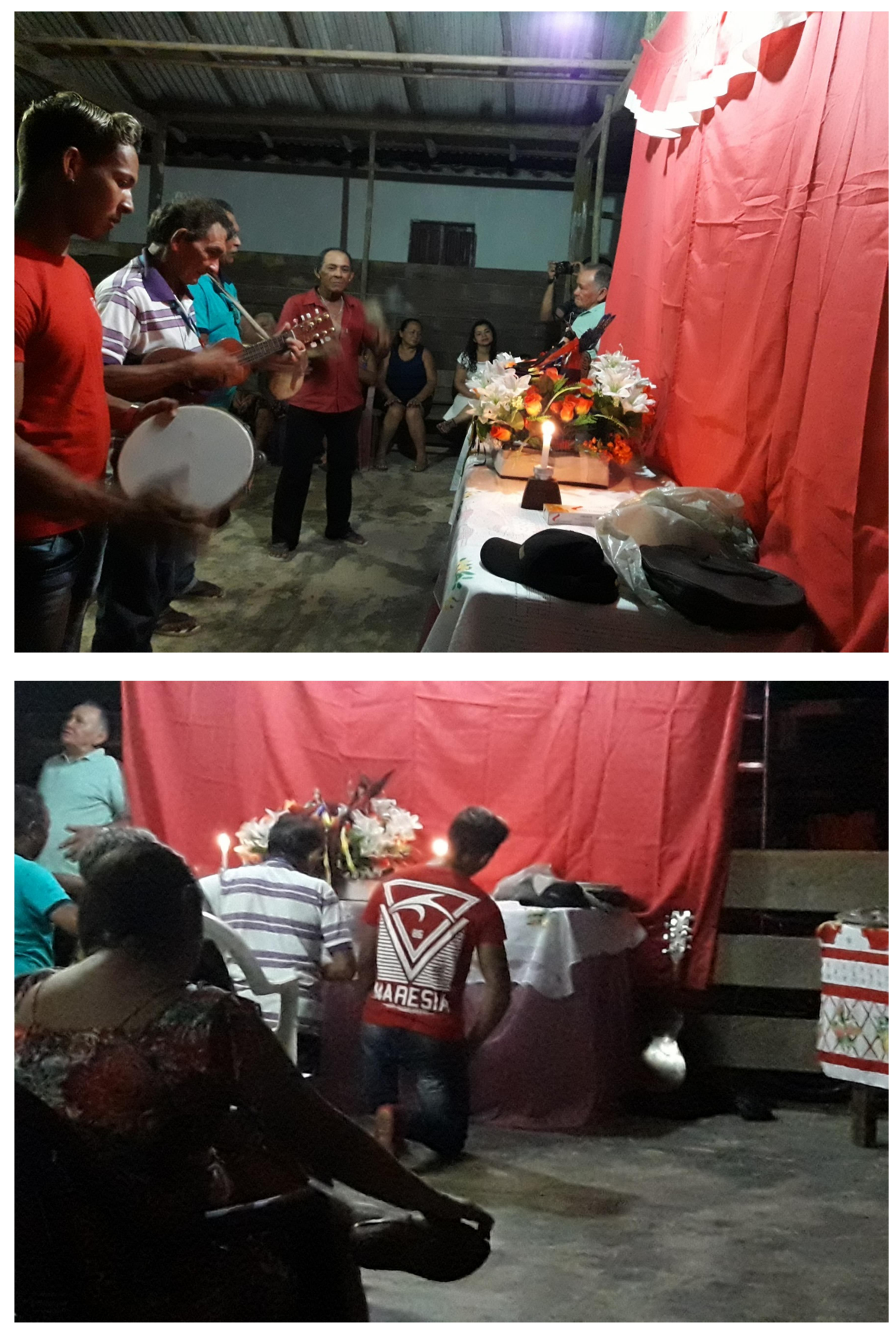